\title{
Impact of Cigarette Smoke Exposure on the Lung Fibroblastic Response after Influenza Pneumonia
}

\author{
Sei Won Lee ${ }^{1,2,3 \star}$, Lokesh Sharma ${ }^{1 *}$, Young Ae Kang ${ }^{1,4}$, Sang-Hun Kim ${ }^{1}$, Sreelakshmi Chandrasekharan ${ }^{1}$, \\ Ashley Losier ${ }^{1}$, Virginia Brady ${ }^{1}$, Santos Bermejo ${ }^{1}$, Nathaniel Andrews ${ }^{1}$, Chang-Min Yoon ${ }^{1}$, Wei Liu ${ }^{1}$, Jung-Yeon Lee ${ }^{1,5}$, \\ Min-Jong Kang ${ }^{1 \ddagger}$, and Charles S. Dela Cruz ${ }^{1 \ddagger}$ \\ ${ }^{1}$ Section of Pulmonary, Critical Care and Sleep Medicine, Department of Internal Medicine, Yale University School of Medicine, \\ New Haven, Connecticut; ${ }^{2}$ Department of Pulmonary and Critical Care Medicine, and ${ }^{3}$ Clinical Research Center for Chronic Obstructive \\ Airway Diseases, Asan Medical Center, University of Ulsan College of Medicine, Seoul, Korea; ${ }^{4}$ Division of Pulmonology, Department \\ of Internal Medicine, Severance Hospital, Institute of Chest Diseases, Yonsei University College of Medicine, Seoul, Korea; and ${ }^{5}$ Division \\ of Pulmonary and Critical Care Medicine, Department of Internal Medicine, Konkuk University Medical Center, Chungju Hospital, \\ Chungju, Korea
}

ORCID IDs: 0000-0003-4814-6730 (S.W.L.); 0000-0003-3040-9029 (L.S.); 0000-0002-5258-1797 (C.S.D.C.).

\begin{abstract}
Influenza viruses can result in significant lung injury with significant morbidity and mortality. In this study, we evaluated the impact of cigarette smoke (CS) exposure on the pulmonary fibroblastic response after influenza infection. We used a murine model in which animals were exposed to CS or room air and subsequently infected with $\mathrm{H} 1 \mathrm{~N} 1$ influenza virus. Inflammatory and fibrotic responses were measured at different time points after influenza infection. Primary fibroblasts were isolated from the lungs of mice and their characteristics were evaluated. Exposure to CS significantly increased the amount of collagen in the lungs of mice infected with influenza virus compared with the nonsmoking group at 30 days after infection. Furthermore, the presence of fibroblast-specific protein-positive cells increased in the lungs of influenza-infected mice that were
\end{abstract}

exposed to CS compared with the infection-alone group. The smoking group also showed delays in weight recovery and higher cell counts in BAL fluid after infection. Active transforming growth factor $\beta 1$ levels in BAL fluid increased in both groups; however, CS-exposed mice had a later surge in active transforming growth factor $\beta 1$ (Day 24). Ex vivo cultures of lung-derived fibroblasts from CS-exposed mice with influenza infection showed rapid proliferation, increased expression of $\alpha$-smooth muscle actin-stained stress fibers, and higher expression of growth factors compared with fibroblasts from room air-exposed lungs after infection. These results suggest that CS exposure changes the fibroblastic potential, leading to increased fibrosis after influenza infection.

Keywords: influenza virus; fibroblast; fibrosis; pneumonia; smoking
Pneumonia due to influenza virus is one of the major causes of morbidity and mortality. Influenza lung infections are estimated to result in $\sim 3-5$ million cases of severe illness, and 250,000-500,000 deaths worldwide (1). In the United States, $\sim 200,000$ people are hospitalized due to influenza every year, with 36,000 annual deaths $(2,3)$. Many complications are associated with influenza virus infection, including pneumonia, acute respiratory distress syndrome, myocarditis, encephalitis, myositis, rhabdomyolysis, and kidney failure. Pneumonia is the most common of these complications and is the leading cause of mortality from influenza (4). In addition, the impact of cigarette smoking on human health is enormous. Globally, 7 million people die every year of smoking-related diseases, including pneumonia (5). Healthy smokers also

(Received in original form January 5, 2018; accepted in final form June 19, 2018)

*These authors contributed equally to this study as first authors.

FThese authors contributed equally to this study.

Supported by National Heart, Lung, and Blood Institutes grants HL126094 and HL103770 (C.S.D.C.), and 1R01HL130283 (M.-J.K.),

Author Contributions: Conception and design: S.W.L., M.-J.K., and C.S.D.C. Experiments: S.W.L., L.S., S.-H.K., S.C., A.L., S.B., N.A., C.-M.Y., W.L., and J.-Y.L. Analysis and interpretation: S.W.L., Y.A.K., M.-J.K., and C.S.D.C. Drafting of the manuscript for important intellectual content: S.W.L., L.S., Y.A.K., V.B., M.-J.K., and C.S.D.C.

Correspondence and requests for reprints should be addressed to Charles S. Dela Cruz, M.D., Ph.D., Section of Pulmonary, Critical Care \& Sleep Medicine, Department of Internal Medicine, Yale University, 300 Cedar Street, TACS441D, New Haven, CT 06513. E-mail: charles.delacruz@yale.edu

Am J Respir Cell Mol Biol Vol 59, Iss 6, pp 770-781, Dec 2018

Copyright $\odot 2018$ by the American Thoracic Society

Originally Published in Press as DOI: 10.1165/rcmb.2018-0004OC on August 15, 2018

Internet address: www.atsjournals.org 


\section{Clinical Relevance}

This work suggests that individuals infected with influenza virus could have an increased likelihood of developing a lung fibroblastic response, especially in the setting of cigarette smoke exposure and/or chronic obstructive pulmonary disease. This work may improve our understanding of a subset of smokers or patients with chronic obstructive pulmonary disease who experience respiratory infections and subsequent development of fibrotic lung changes.

experience exaggerated symptomatic responses after viral infections. In addition, increased symptomatology and mortality have been observed in otherwise healthy, influenza-infected smokers, and smoking was found to be an important risk factor in the H1N1 influenza epidemic in healthy young military recruits (6-8). Pneumonia can usually be completely resolved to a pre-illness state (9), but some loss of lung function combined with fibrotic changes has been reported in some severe cases (10).

Early activation of fibrogenesis due to lung injury has been described during influenza virus infection (11). Influenza virus infection in mice can cause extensive damage to the airways and alveolar epithelium, especially with a murinized version of a pandemic H1N1 strain of influenza A virus such as PR8 (12). An epidemiologic study found an increased trend in mortality from influenza infection in smokers (13). Smokers had an increased incidence of infection and were associated with more severe disease than nonsmokers (14). Overall, these epidemiologic studies suggest that cigarette smoking has an adverse impact on the clinical course of an influenza virus infection; however, not much is known about the chronic consequences of smoking on pulmonary morbidity in influenza pneumonia (15).

Our previous work demonstrated that lung responses to external stimuli such as viral infections and cigarette smoke (CS) exposure result in increased lung inflammation and tissue damage (16). In addition, it has been shown that CS exposure can contribute to lung fibrosis (17-19). CS might adversely affect normal lung repair processes that are needed to limit potential deleterious post-viral-exposure lung sequelae such as tissue destruction and fibrosis. The mechanisms by which CS results in lung remodeling and fibrotic changes after respiratory viral infections, however, remain poorly understood.

In this study, we hypothesized that CS exposure dysregulates the fibroblast characteristics and contributes to enhanced lung fibrogenesis after influenza pneumonia. Here, we show the effects of CS exposure on in vivo and ex vivo fibroblastic responses after inflammation and lung destruction in influenza-virus-infected mice. Our findings highlight the significant contribution of CS exposure in enhancing the fibroblast characteristics after a secondary insult such as influenza virus infection.

\section{Methods}

\section{Mice}

Wild-type male C57BL/6 mice (Jackson Labs) were bred at Yale University in specificpathogen-free conditions. All animal experiments were conducted with the approval of the Institutional Animal Care and Use Committee of the Yale School of Medicine.

\section{CS Exposure and Viral Infection}

Nine- to 10-week-old mice were exposed to room air (the nonsmoking [NS] group) or CS (the CS group) via a smoking apparatus as previously described $(16,20)$. During the first week, the mice received a half cigarette twice a day to allow for acclimation, and then they received three cigarettes per day (one cigarette/session, three sessions/day) for the remainder of the exposure. After 2 weeks of CS exposure, the mice were lightly anesthetized with ketamine/xylazine, and 100 plaque-forming units (pfu) of A/PR8/34 influenza (equivalent to 0.5 median lethal dose $\left[\mathrm{LD}_{50}\right]$ in $\mathrm{C} 57 \mathrm{BL} / 6 \mathrm{~J}$ mice) was administered via nasal aspiration in $50 \mu \mathrm{l}$ of PBS using previously described techniques (21). Smoking was continued for the CS group in the same manner after influenza infection. The body weights of the mice were measured individually every 3 days before they were killed. Influenza virus was quantified in lung lysates by quantitative PCR as described in our previous publication (16). All experiments were repeated at least three times unless otherwise indicated.

\section{BAL}

The mice were anesthetized and then killed by urethane injection, and the tracheas were cannulated and perfused twice with 0.8-ml aliquots of cold sterile PBS. The cellular contents and BAL fluid were separated by centrifugation, and the BAL fluid was stored in aliquots at $-80^{\circ} \mathrm{C}$ for further analysis. Quantification of transforming growth factor $\beta 1$ (TGF- $\beta 1$; R\&D) in BAL fluid was determined using commercial ELISA kits according to the manufacturer's instructions after $5 \times$ concentration using commercialized kits (Merck).

\section{Lung Collagen Content}

After BAL was performed, the mouse lung tissues were harvested as previously described (22). In hematoxylin-andeosin-stained lung sections, the collagen in the entire right lung was quantitated using the Sircol Collagen Assay Kit (Biocolor Ltd.) according to the manufacturer's instructions.

\section{Immunohistochemistry}

To assess the number of fibroblasts in vivo, immunohistochemistry (IHC) of fibroblastspecific protein 1 (FSP1), a member of the calmodulin S100 troponin C superfamily (23), was performed using rabbit antimurine FSP1 antibody (Cell Signaling) as previously described (24).

\section{Primary Fibroblast Culture}

Primary lung fibroblasts were isolated from two mice in each group with or without influenza infection or smoking, as previously described $(25,26)$. The third passage of cells was used for all experiments to achieve sufficient cell numbers for in vitro studies. For proliferation analyses, we used WST-1 reagent (Roche) according to the manufacturer's protocol after plating 5,000 cells per well in a 96-well plate.

This experiment was repeated three times.

\section{Semiquantitative RT-PCR}

Total RNA was isolated from the fibroblasts using the RNeasy Plus Mini Kit (Qiagen). After synthesis of cDNA, quantitative PCR was performed using SsoAdvanced Universal SYBR Green Supermix (Bio-Rad), and the specific primers for $\alpha$-smooth muscle actin ( $\alpha$-SMA), collagen 1a1 (col1a1), collagen 1a2 (colla2), connective tissue growth factor (CTGF), vascular endothelial growth factor (VEGF), plateletderived growth factor (PDGF), TGF- $\beta 1$, and influenza. We used $18 \mathrm{~S}$ ribosomal 
RNAs as housekeeping genes. The primer sequences are listed in Table 1.

\section{Immunofluorescence}

Isolated primary fibroblasts were cultured in chamber slides, fixed, permeabilized, and incubated with the rabbit anti-mouse $\alpha$-SMA antibody (Abcam).

\section{Western Blotting}

Fibroblast lysates were prepared and the total protein concentration was determined. Equal amounts of sample proteins were used for Western blot analysis.

TGF- $\beta$ antibody blocking experiments. Mice were either exposed to CS or remained in normal air for 3 weeks and then infected with influenza as described previously. CS-exposed mice were randomized to receive either anti-TGF- $\beta$ antibody or isotypic control IgG (Bio X Cell) at $1 \mathrm{mg}$ per mouse on alternative days starting on Day 12 after infection. The mice were measured for weight changes every day until Day 28. The mice were killed on Day 28 to harvest lung tissues for mRNA/protein measurements and lung pathology.

\section{Statistical Analysis}

Statistical evaluations were undertaken with Prism 7 software (GraphPad Software, Inc.). As appropriate, the groups were compared using a two-tailed Student's $t$ test or a nonparametric Mann-Whitney $U$ test. All experiments were repeated three times unless indicated otherwise. Values are expressed as mean \pm SD unless stated otherwise. Statistical significance was defined at a level of $P<0.05$.

\section{Results}

\section{Increased Inflammatory Response and Slow Recovery of Body Weight after Influenza Virus Infection in CS-exposed Mice}

Mice were exposed to either CS or ambient room air (NS) for 2 weeks and subsequently infected intranasally with influenza virus. The total BAL fluid cell counts increased after influenza virus infection over the first 9 days, but the total white blood cell counts were not significantly different between the CS and NS groups (Figure 1A). The total cell counts of the CS group remained significantly higher than those of NS group at 12-21 days after infection. The peak neutrophil counts were noted at 6 days after infection in both groups, and the neutrophil counts in the CS group were higher than those of the NS group (7.35 \pm 1.70 vs. $5.34 \pm 1.94, P=0.04$; Figure $1 \mathrm{~B}$ ) at this time point. This elevated neutrophilic inflammation continued at Days 9 and 12 after infection in the CS group compared with the NS group (Figure 1B). The macrophage cell counts were higher in the CS group than in the NS group at Days 12-21 after infection (Figure 1C). The peak lymphocyte counts were noted to be at 12 days after infection in both groups, and were not significantly different between the groups (Figure 1D).

In addition, during the course of viral infection, the mice lost weight by $\sim 20 \%$

Table 1. Primer Sequences for Quantitative PCR

\section{Gene Name}

Col1a1

Col1a2

CTGF

PDGF- $\alpha$

PDGF- $\beta$

$\alpha-S M A$

Influenza matrix

TGF- $\beta$

Forward
Reverse
Forward
Reverse
Forward
Reverse
Forward
Reverse
Forward
Reverse
Forward
Reverse
Forward
Reverse
Forward
Reverse

Sequences

5'-GCTCCTCTTAGGGGCCACT-3'
5'-CCACGTCTCACCATTGGGG-3'
5'-GTAACTTCGTGCCTAGCAACA-3'
5'-CCTTTGTCAGAATACTGAGCAGC-3'
5;-GGGCCTCTTCTGCGATTTC-3'
5'-ATCCAGGCAAGTGCATTGGTA-3'
5'-GAGGAAGCCGAGATACCCC-3'
5'-TGCTGTGGATCTGACTTCGAG-3'
5'-AAGTGGAGACAATAGTGACCCC-3'
5'-CATGGGTGTGCTTAAACTTCG-3'
5'-GCTCCTCTTAGGGGCCACT-3'
5'-CCCAGACATCAGGGAGTAATG-3'
5' AAGACCAATCCTGTCACCTCTGA 3'
5' CAAAGCGTCTACGCTGCAGTCC 3'
5'-AGACCACATCAGCATTGAGTG-3'
5'-GGTGGCAACGAATGTAGCTGT-3'

Definition of abbreviations: $\alpha$-SMA $=\alpha$-smooth muscle actin; col1a1 = collagen 1a1; col1a2 = collagen 1a2; CTGF = connective tissue growth factor; PDGF = platelet-derived growth factor; TGF- $\beta=$ transforming growth factor $\beta$. from their baseline. Interestingly, weight recovery was significantly delayed in the CS group, and weight loss did not recover fully in the CS group even after 30 days of infection (Figure 1E). The weight difference between CS and NS mice was statistically significant at Days 27 and 30 after infection ( $P=0.02$ and $P=0.008$, respectively).

To evaluate whether the above responses were affected by the alteration of viral clearance, the influenza viral loads were measured by quantitative PCR of influenza in the lungs. The peak viral load was noted at similar levels at 6 days after infection in both groups. At the dose of virus used for the infections, there was a modest increase in viral load in the CS group at Day 3 after infection compared with the NS control group (Figure 1F). At 9 days after infection, no viral mRNAs were detected in either group, and no significant difference in viral clearance was observed between the groups (Figure 1F). Taken together, these data demonstrate that CS exposure adversely affected pulmonary inflammatory responses after influenza infection, with persistent macrophage accumulation that was associated with impaired recovery from infection, manifested as decreased weight gains in the recovery phase.

\section{CS Exposure Exacerbates the Lung Fibroblastic Response after Influenza Virus Infection}

Lung tissues were harvested at various time points after viral infection in mice previously exposed to CS or room air (NS). To evaluate overall lung fibrotic responses, the amount of total collagen in the lungs was measured after viral infection. Influenza infection alone induced a modest increase of collagen accumulation in the lungs (Figure 2A). The amounts of collagen were not significantly different between the CS and NS groups at 15 days after infection (93.2 $\pm 12.2 \mu \mathrm{g}$ vs. $81.4 \pm 30.1 \mu \mathrm{g} ; P>$ $0.05)$. However, the amounts of collagen were significantly increased in the CS group compared with the NS group at 30 days after infection $(144.7 \pm 26.9 \mu \mathrm{g}$ vs. $99.5 \pm$ $24.3 \mu \mathrm{g} ; P=0.007)$. The amounts of collagen at Day 30 after infection were also significantly higher than at baseline before infection in both groups $(P<0.001$ and $P=0.005$, respectively; Figure $2 \mathrm{~A}$ ). There was a marked increase of Masson Trichrome histological (blue) staining in the CS group 30 days after influenza infection (Figure 2B). The mRNA levels of collagen, including colla1, col1a2, and 
A

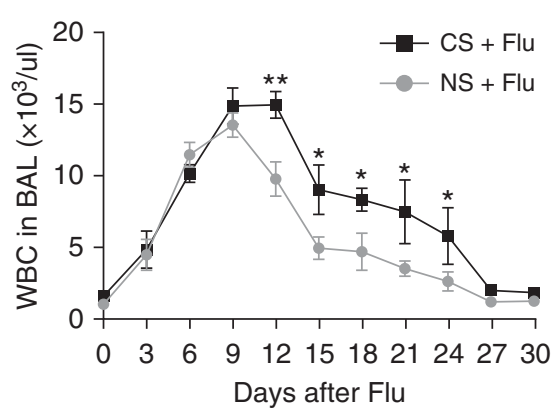

D

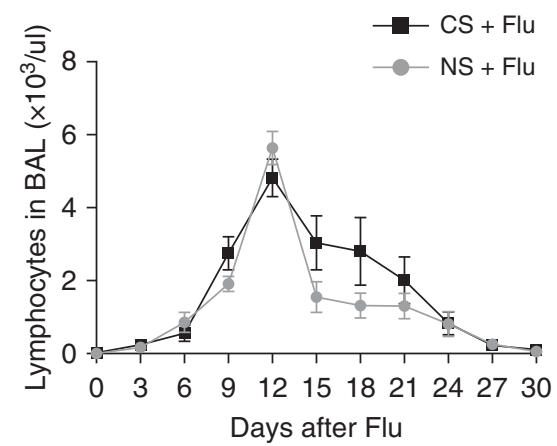

B

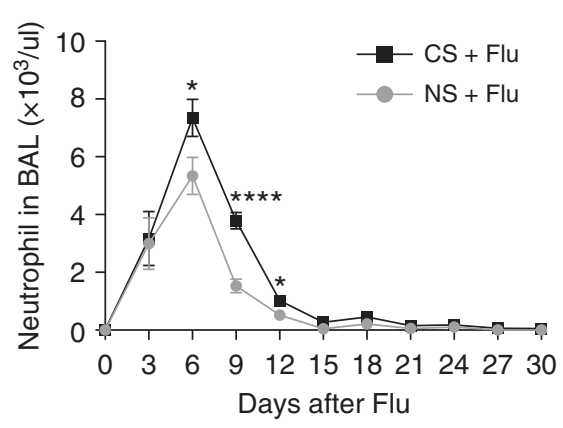

E

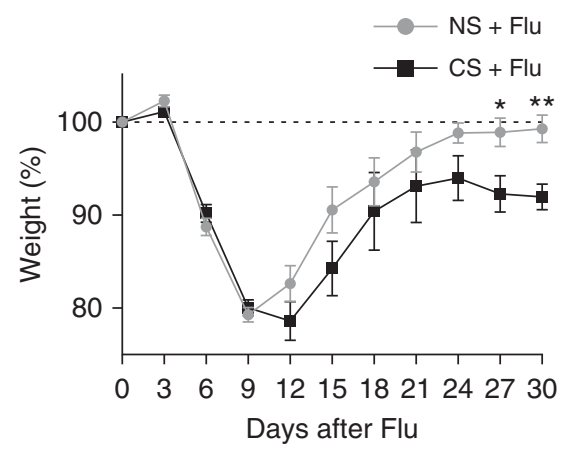

C

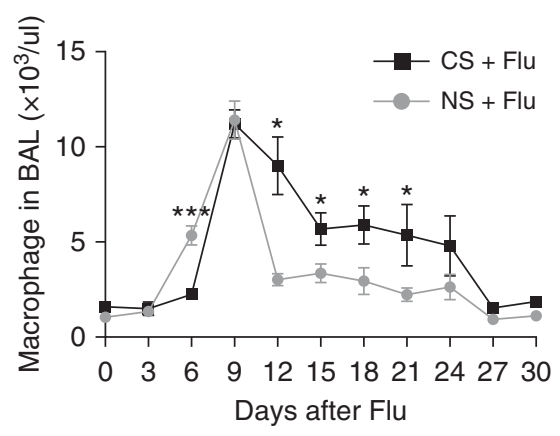

$\mathbf{F}$

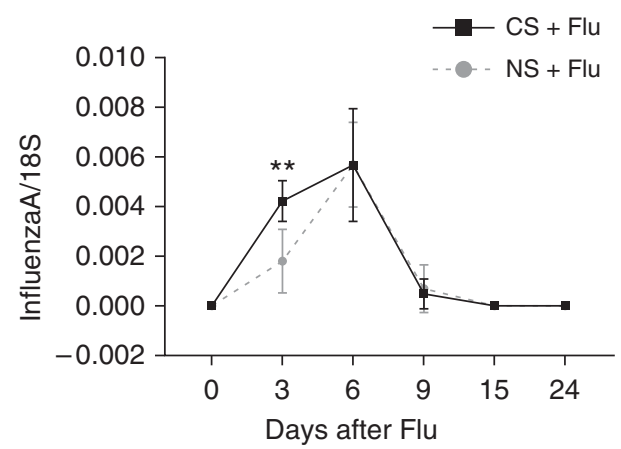

Figure 1. Cigarette smoke (CS) exposure leads to a heightened inflammatory response, delayed recovery of body weight, and an initial modest increase in viral titers after influenza infection. Mice preexposed to smoke were infected with $\sim 10$ plaque-forming units (pfu) of influenza A virus and continued to get smoke exposure until they were killed at different time points. (A) Total number of inflammatory cells in the BAL of mice. (B-D) Numbers of neutrophils $(B)$, macrophages $(C)$, and lymphocytes $(D)$ in the BAL of influenza-infected mice with or without CS exposure. (E) Recovery of weight was delayed in the CS group, and the difference between the CS and nonsmoking (NS) groups became significant from Day 27 after infection. $(F)$ The levels of influenza A virus mRNA were higher in the lung homogenates of CS-exposed mice on Day 3 after infection, but there was no significant difference between the two groups after Day 6 . Data are from one of at least three independent experiments performed with $n=4-6$ in each group at each given time point. ${ }^{\star} P<0.05 ;{ }^{\star \star} P<0.01 ;{ }^{\star \star \star} P<0.001$; ${ }^{\star \star \star \star} P<0.0001$ comparing $\mathrm{CS}$ and NS groups at the same time point. WBC $=$ white blood cell.

col3a1, were also increased significantly from baseline in both groups at 9 and 15 days after influenza infection (Figure 2C). This increase in collagen gene expression noted at the early time points after influenza infection (Figure 2C) is reflected by the increased collagen content in the lung that was maximally noted at Day 30 after infection (Figure 2A). Interestingly, each of these collagen genes showed a significant increase in the CS group compared with the NS group at 9 days (colla1, colla2, and col3a1) and 15 days (colla2) after influenza infection (Figure 2C). Overall, these data demonstrate that CS exposure in vivo enhances the fibrogenic responses in the lungs after influenza virus infection.

\section{Enhanced Active TGF- $\beta$ with CS Exposure and Viral Infection}

TGF- $\beta$ plays a central role in tissue healing, repair, and fibrosis. We investigated the levels of total and active TGF- $\beta 1$ in the BAL samples from mice infected with influenza with or without smoke exposure. Influenza infection increased active TGF- $\beta 1$ in BAL fluids at 6 days after infection in both the $\mathrm{CS}$ and NS groups. However, the levels were significantly higher in the infected NS group $(32.9 \pm 17.0$ vs. $16.9 \pm 11.0 \mathrm{pg} / \mathrm{ml}$; $P=0.002)$ than in the CS group with infection. In a similar manner, total TGF- $\beta 1$ peaked at Day 6 after viral infection, with higher levels of total TGF- $\beta 1$ observed in the infected NS group compared with CS-exposed mice with influenza virus infection (Figure 3B). The initial surge of active TGF- $\beta$ that was notably lower in the CS-exposed mice with influenza virus infection compared with room airexposed mice with influenza virus infection is consistent with the antiinflammatory effect of active TGF- $\beta 1$ and the observed heightened inflammation noted in the lungs of CS-exposed infected mice, as shown in
Figure 1. The levels of active TGF- $\beta 1$ significantly decreased by 9 days after infection in both groups, and the active TGF- $\beta 1$ levels remained at baseline from 9 to 12 days after infection. Interestingly, a second surge in the active TGF- $\beta 1$ levels was observed at 15 days in infected mice that were exposed to CS, and peaked at 24 days after infection. At this time point, the TGF- $\beta 1$ levels were significantly higher in the CS group (23.2 \pm 5.7 vs. $6.8 \pm 4.1 ; P=0.02$;

Figure 3A). However, the total TGF- $\beta$ levels remained comparable between the two groups at the later phase of infection, suggesting a specific activation mechanism present only in the CS-exposed group (Figure 3B). Collectively, these data suggest that CS exposure in vivo dysregulates the physiological TGF- $\beta$ activation that contributes to the increased fibrotic response in CS mice after influenza virus infection. 
A

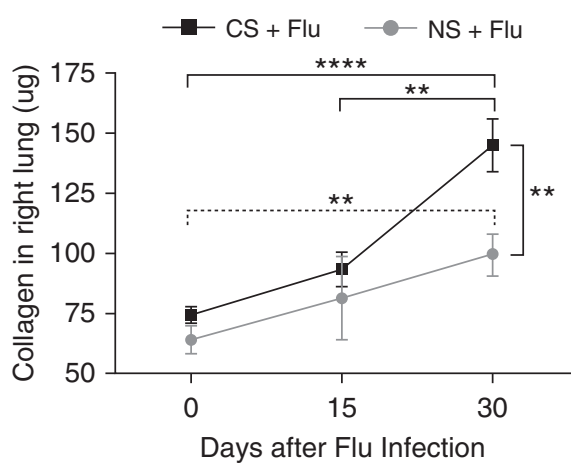

B

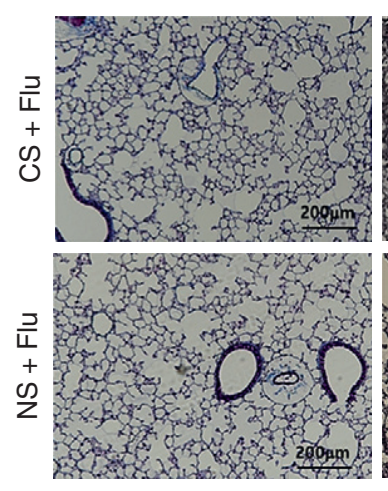

0

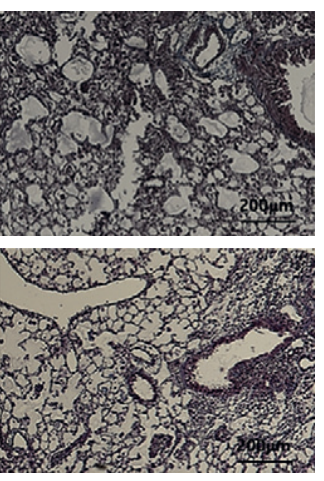

15

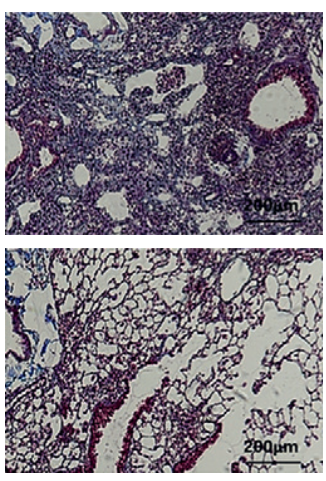

30

Days after Flu Infection

D

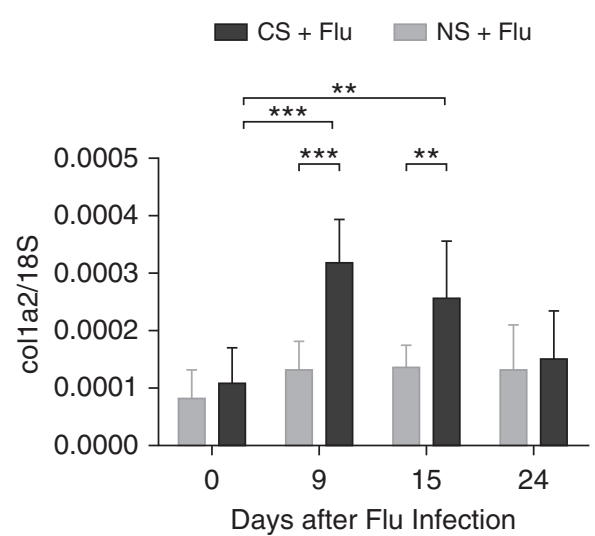

E

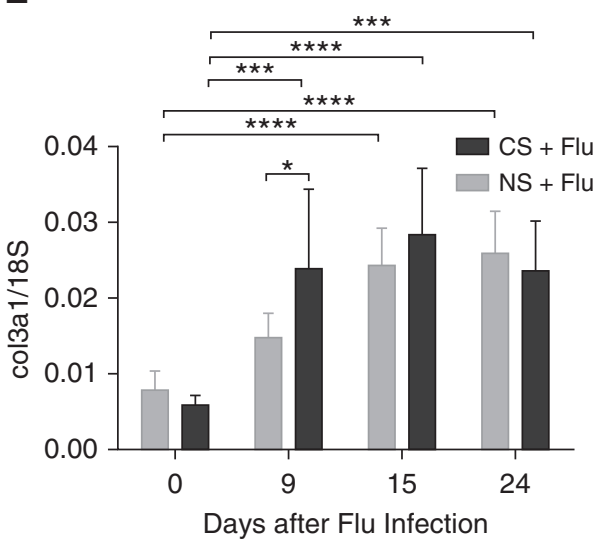

Figure 2. CS exposure exacerbates lung fibrosis during influenza virus infection. Wild-type mice were exposed to CS for 2 weeks and then infected with 10 pfu of influenza virus. Smoking continued after viral infection. (A) The collagen content in the right lung was measured by Sircol assay on Days 15 and 30 after infection. Lungs were harvested from influenza-infected mice that were either exposed to smoke or remained in room air at the indicated time points. (B) Lung sections were subjected to Masson's trichrome staining, and representative sections from three independent experiments are shown at a total magnification of $\times 40$. The expression of collagen-related genes was measured on Days 9, 15, and 24 after infection. Scale bars: $200 \mu m$. ( $C-E$ ) Expression of collagen 1a1 (col1a1) $(C)$, col1a2 $(D)$, and col3a $(E)$ was normalized with the expression of $18 S$ in the lung tissue. Data are from one of at least three independent experiments performed with $n=4-6$ in each group at each given time point. ${ }^{\star} P<0.05 ;{ }^{* \star} P<0.01 ;{ }^{\star \star \star} P<0.001 ;{ }^{\star \star \star \star} P<0.0001$.

\section{Smoking Increases FSP ${ }^{+}$Cells in Lungs after Influenza Virus Infection}

Fibroblasts are important mediators of pathological fibrotic accumulation and the major source of extracellular matrix (ECM) proteins, such as collagen (27). To assess the numbers and distribution of fibroblasts in the lungs, IHC staining for FSP1 was performed on lung sections. The number of FSP1 ${ }^{+}$cells was significantly higher in the CS group than in the NS group at both 15 days ( $1775 \pm 314$ vs. $1033 \pm 216$ cells $\left./ \mathrm{mm}^{2} ; P<0.001\right)$ and 30 days $(2016 \pm$ 287 vs. $794 \pm 344$ cells $\left./ \mathrm{mm}^{2} ; P<0.001\right)$ after infection (Figures $4 \mathrm{~A}$ and $4 \mathrm{~B}$ ). The IHC results showed an increased number of cells with FSP1 staining, suggesting the increased presence of fibroblasts surrounding the bronchial walls in the CS group at 30 days after influenza virus infection. On Day 15 after virus infection, inflammatory infiltration and exudates were observed in both groups, suggesting a pathological condition that resembles viral pneumonia and acute respiratory distress syndrome (Figure 4).

\section{Increased Expression of $\alpha$-SMA and col1a in Primary Fibroblasts Isolated from CS-exposed Mice with Influenza Infection}

To further characterize the fibroblasts in the CS-exposed and influenza-infected mice, fibroblasts were isolated from four different exposure groups: control, smoking only, influenza infection, and influenza infection with smoking. The fibroblasts isolated from mice exposed to CS and influenza infection showed increased expression of $\alpha$-SMA RNA (Figure 5A) as well as increased amounts of protein (Figure 5B). Furthermore, fluorescent IHC evaluation of $\alpha$-SMA proteins revealed remarkable findings. Specifically, the presence of stressed fibers was minimally increased after CS exposure alone compared with NS controls (Figures 5C and 5D). In addition, influenza virus infection by itself induced a modest but statistically significant increase in stressed fibers in the pulmonary fibroblasts (Figures 
A

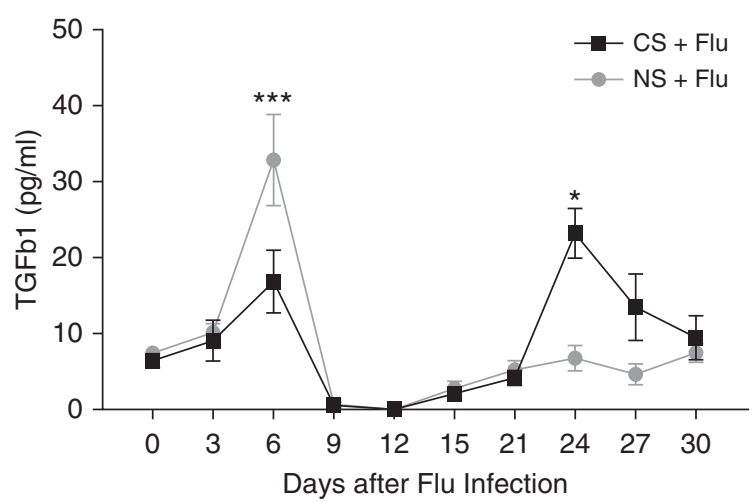

B

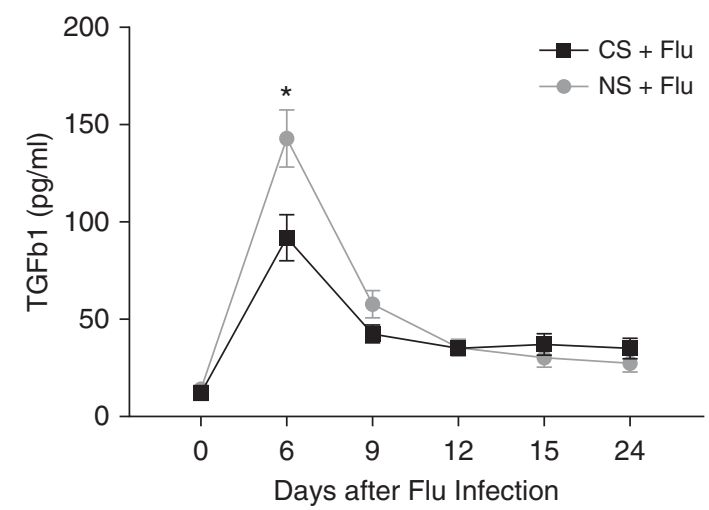

Figure 3. CS exposure caused different levels of transforming growth factor $\beta$ (TGF- $\beta$ ) in BAL fluid after influenza infection. The levels of TGF- $\beta$ were measured in the BAL samples of CS-exposed and influenza-infected mice at the indicated time points. $(A$ and $B)$ Total TGF- $\beta$ levels $(A)$ and active TGF- $\beta$ levels $(B)$ in BAL fluid; $n=>4$ mice in each group at each time point. The data represent the mean \pm SD for a minimum of four mice at each time point. Data are from one of at least two independent experiments. ${ }^{\star} P<0.05$; ${ }^{\star \star \star} P<0.001$ comparing CS and NS groups at the same time point.

5C and 5D). Surprisingly, this influenza virus-induced increase of stressed fibers was significantly enhanced in the pulmonary fibroblasts after CS exposure in vivo (Figures $5 \mathrm{C}$ and $5 \mathrm{D})$. In accordance with these findings, the expression of colla RNA also increased significantly in the fibroblasts isolated from mice exposed to both CS and influenza infection (Figures 5E and $5 \mathrm{~F}$ ). It is intriguing that the fibrogenic responses of pulmonary fibroblasts were enhanced after CS exposure in vivo with concomitant influenza virus infection.

\section{CS Exposure Enhances the Proliferation Rates and Expression of Growth Factors in Primary Lung Fibroblasts}

To further understand the underlying mechanisms of increased fibrotic response and accumulation of fibroblasts in the lungs, we cultured lung fibroblasts from NS and CS mice with influenza virus infection. We characterized these cells for their proliferative responses using a colorimetric WST-1 assay. Interestingly, the fibroblasts isolated from mice exposed to CS and influenza virus infection showed higher proliferation rates than those isolated from virus-infected NS mice. Significant differences in proliferation was observed at Day 3, and these further increased at Day 4 between CS-exposed and NS mice that were infected with influenza virus (Figure 6A). The mRNA levels of several growth factors, such as CTGF, VEGF- $\alpha$, VEGF- $\beta$, PDGF- $\alpha$, and PDGF- $\beta$, were higher in fibroblasts isolated from the mice that were exposed to CS and influenza infection than in those isolated from mice exposed to influenza infection alone (Figure 6B). These data suggest that exposure to CS increases the proliferative response in fibroblasts, which is mediated by the increased expression of various growth factors. Taken together, our data suggest that smoking not only increased the proliferative response in fibroblasts obtained from influenza-infected lungs but also increased their activity, as measured by the increased expression of collagen and growth factors in fibroblasts, resulting in an increased fibrotic response in the lungs.

\section{Anti-TGF- $\beta$ Antibody Treatment in CS-exposed Mice Ameliorates the Fibrotic Response and Improves Recovery during Influenza Virus Infection}

To determine the role of TGF- $\beta$ in the effects of CS and influenza infection on lung fibrotic responses, we performed antibody neutralization experiments using anti-TGF- $\beta$ antibodies in our model. Interestingly, mice that were treated with anti-TGF- $\beta$ antibodies ( $1 \mathrm{mg}$ per mouse every other day starting 12 days after infection) showed a marked improvement in overall morbidity, as evidenced by a significantly quicker recovery of weight loss compared with control IgG-treated mice after smoke exposure (Figure 7A). The early recovery of anti-TGF- $\beta$ antibody-treated mice was associated with amelioration of many markers of an exaggerated fibrotic response. Although the mRNA levels of SMA were significantly decreased in the anti-TGF- $\beta$ antibody-treated mice, a trend toward a reduction of SMA protein levels was observed in these mice (Figures 7C and 7D). We also observed a partial reduction in collagen deposition, and the presence of $\mathrm{FSP}^{+}$cells in the lung tissues of mice that were treated with anti-TGF- $\beta$ antibodies (Figures 7B and 7D). Other fibrotic changes were not completely blocked by the use of anti-TGF- $\beta$ antibodies, as we observed only a partial decrease in collagen deposition and accumulation of $\mathrm{FSP}^{+}$cells, which were significantly increased by smoking (Figures 7B and 7F). Taken together, our data suggest that the fibrotic response from CS exposure and influenza virus infection can be at least partially decreased with anti-TGF- $\beta$ antibody treatment.

\section{Discussion}

Deleterious effects of CS exposure on the lungs are well documented; however, the underlying mechanisms, especially after a respiratory viral infection, remain poorly understood. CS exposure has been shown to impair adaptive humoral and cellular responses, and exaggerate proinflammatory and innate immune responses to various stimuli, including respiratory pathogens. CS exposure by itself has been shown to contribute to lung fibrosis $(17,18)$. However, our understanding of how CS exposure affects physiological tissue 
A

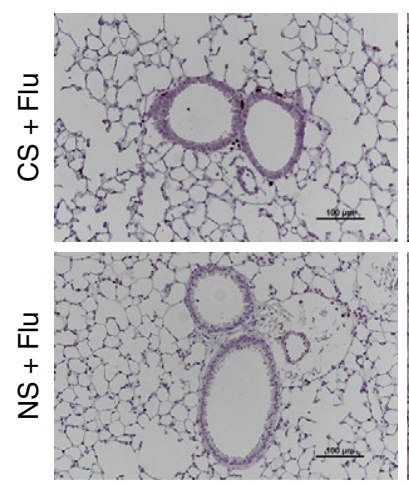

0

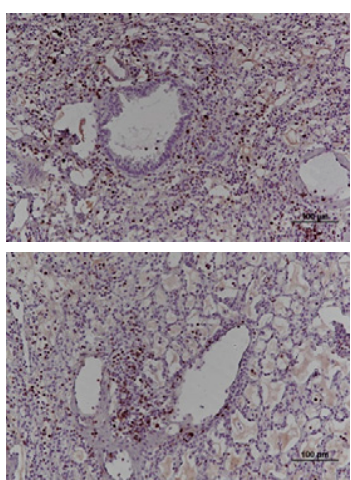

15

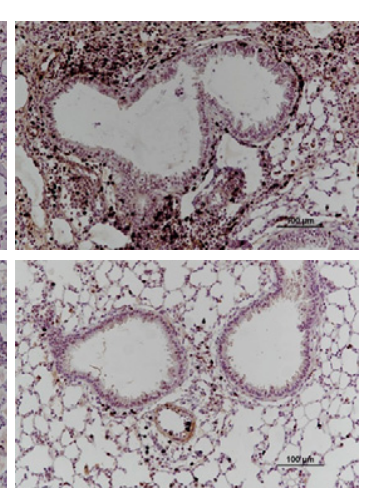

30

Days after Flu Infection

\section{B}

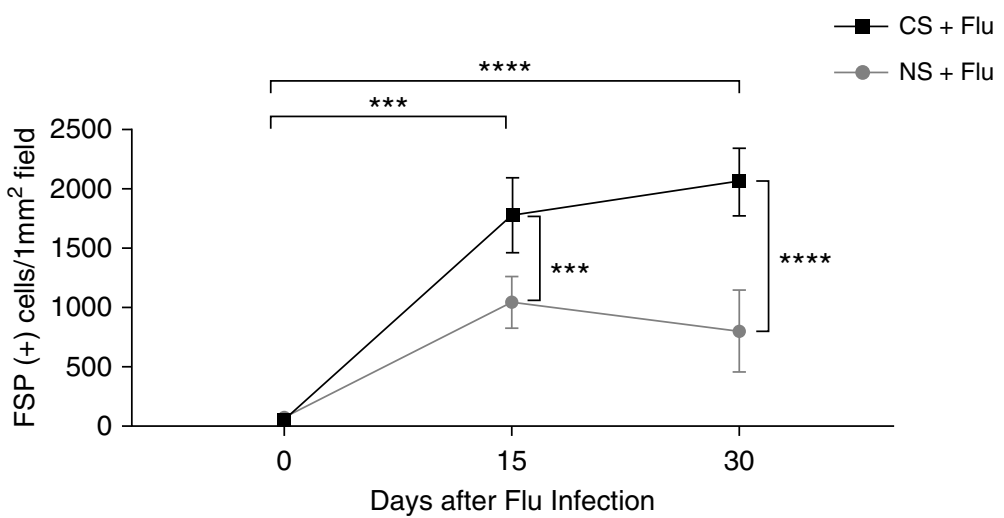

Figure 4. Increased fibroblast-specific protein (FSP) staining in the lungs of CS-exposed mice upon influenza virus infection. Lung sections from CS-exposed mice infected with influenza on Days 15 and 30 were subjected to immunohistochemistry staining to detect $\mathrm{FSP}^{+}$cells. (A) Representative immunohistochemistry images are shown. $(B)$ The numbers of $\mathrm{FSP}^{+}$cells were quantified. Data are from one of at least three independent experiments, with $n=4-6$ mice in each group at each given time point. ${ }^{\star \star \star} P<0.001$; ${ }^{* \star \star \star} P<0.0001$. Scale bars: $100 \mu \mathrm{m}$.

damage/repair responses after viral infection remains limited. In this study, we report that CS exposure exacerbated fibrotic responses in the lungs after influenza viral infection, as measured by increased expression and accumulation of collagen in the lungs. These changes correlated with an increase in active TGF- $\beta 1$ levels in BAL fluid at a later phase of infection. Furthermore, in ex vivo lung fibroblasts, increased proliferation and features of myofibroblasts were observed in influenza virus-infected mice that were exposed to CS. These fibrotic responses were associated with an initial increased recruitment of neutrophils and a later increased, protracted macrophage response after virus infection in the CS-exposed group. It should also be noted that no major changes in viral clearance were observed in the two groups, but alterations in the inflammatory and fibrotic responses were sufficient to impair normal recovery from influenza infection in CS-exposed mice. Our study is the first to demonstrate that CS exposure in vivo causes significant exacerbations in lung fibrotic responses after influenza virus infection, which is associated with dysregulation of fibroblast characteristics.

The fibroblastic response after lung inflammation has been described in both human and animal models of lung diseases. One study found that after acute respiratory distress syndrome, a classical form of severe acute pulmonary inflammatory disorder,
$64 \%$ of the patients had evidence of pulmonary fibrosis and $20 \%$ had severe fibrosis (28). In a study using mice infected with influenza virus, the mice initially exhibited pneumonic features, and many showed fibrosis after virus infection (29). As noted in the Introduction, CS has been identified as an important adverse factor in the clinical course of an influenza virus infection $(6-8,13,14)$. In this regard, it is intriguing that our experimental model recapitulates human pathologies that are observed in smokers with concomitant influenza viral pneumonia, including more severe inflammation and tissue-damage responses. Our model of CS exposure and influenza virus infection showed evidence of the synergistic effect of the two stimuli on lung fibrogenesis. Our findings regarding the role of CS exposure in lung fibrogenic responses have important implications related to postviral lung infections that can contribute to the pathogenesis of long-term sequelae such as pulmonary fibrosis, wherein CS exposure is a risk factor.

It is intriguing that the levels of TGF- $\beta 1$, an important mediator of fibrosis and antiinflammation, showed a different biphasic pattern after influenza infection in the NS controls compared with the CSexposed group. Specifically, CS exposure in vivo initially reduced TGF- $\beta 1$ levels, which correlated with the enhanced inflammatory lung response in the animals exposed to CS and viral infection compared with those exposed to either CS or viral infection alone. Interestingly, CS exposure resulted in a second surge of significantly increased levels of the active form of TGF$\beta 1$, which was not observed in the mice that remained in control air (Figure 3A). This second surge in active TGF- $\beta 1$ levels may have contributed to the significantly increased fibrotic responses at Day 30, as assessed by increased collagen deposition in the lungs. It is known that TGF- $\beta 1$ contributes to tissue healing after inflammation and injury by virtue of its antiinflammatory and fibrotic properties (30). TGF- $\beta 1$ knockout mice showed rapid wasting of weight and excessive multifocal inflammatory responses. Massive amounts of lymphocytes and macrophages infiltrated primarily the heart and lungs, leading to lethal cardiopulmonary complications (31). TGF- $\beta 1$ is a major stimulator of tissue fibrosis and contributes to fibroblast proliferation and the 
A

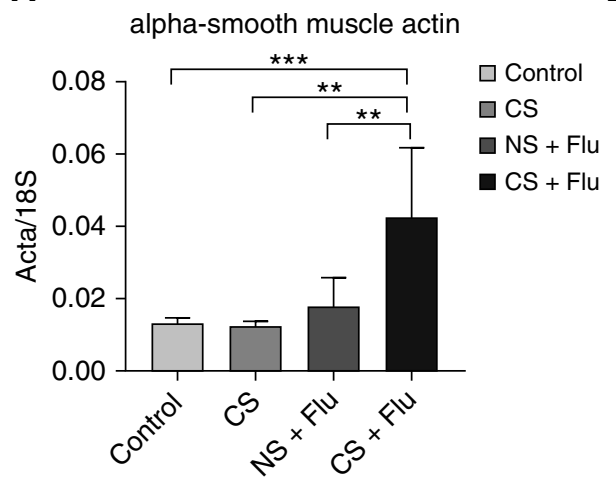

B

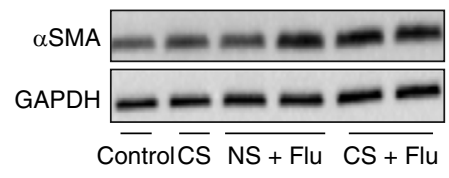

alpha-smooth muscle actin

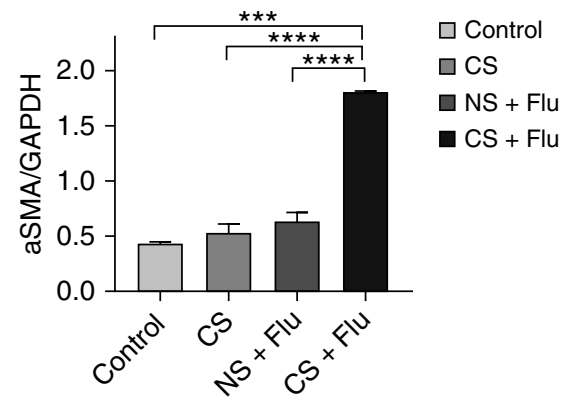

D
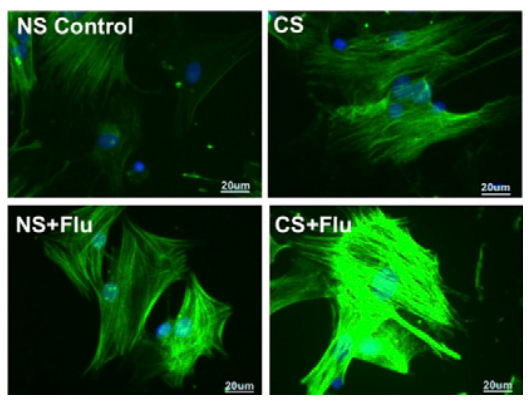

col1a1

$\mathbf{F}$

$\mathbf{E}$

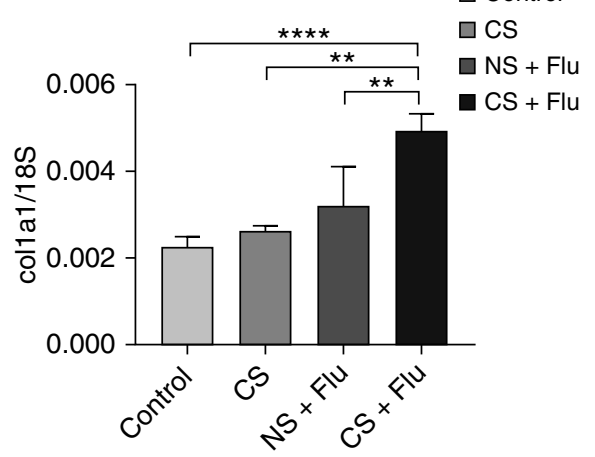

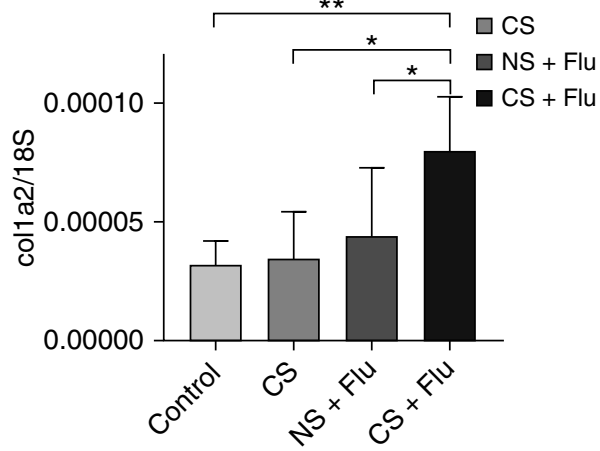

Figure 5. Ex vivo fibroblasts obtained from CS-exposed mice with influenza show increased markers of myofibroblasts. Primary fibroblasts were obtained from influenza-infected mice that were either exposed to CS or remained in room air. Fibroblasts from healthy mice and mice that were exposed to smoke but received no virus infection served as controls. (A) The mRNA levels of $\alpha$-smooth muscle actin (SMA) were measured in fibroblasts. (B) The protein levels of $\alpha$-SMA were measured by Western blot analysis (top), and arbitrary densitometry units for $\alpha$-SMA were standardized by GAPDH levels (bottom). (C) Immunofluorescence staining of $\alpha$-SMA is shown in lung fibroblasts obtained from different groups at $\times 40$ magnification. Scale bars: $100 \mu \mathrm{m}$. (D) At higher magnification $(\times 200)$, stress fibers are visible in the fibroblasts obtained from CS- and influenza-exposed mice. Scale bars: $20 \mu \mathrm{m}$. ( $E$ and $F$ ) The mRNA levels of genes related to collagen were measured in these fibroblasts, and the levels of col1a1 $(E)$ and col1a2 $(F)$ were normalized to 18S. All figures are from representative data of three or more independent experiments. In vitro experiments were performed in triplicate wells. ${ }^{\star} P<0.05$; ${ }^{\star \star} P<0.01$; ${ }^{* \star \star} P<$ $0.001 ;{ }^{\star \star \star \star} P<0.0001$.

production of extracellular matrix components, particularly collagen and fibronectin, while reducing the degradation of those components. In this regard, it should be noted that exposure to CS resulted in a heightened TGF- $\beta$ response in the lungs at 3 weeks after influenza virus infection, which was correlated with lung fibrogenesis. Furthermore, this heightened TGF- $\beta 1$ production was associated with more enhanced fibrogenic responses of pulmonary fibroblasts.

In the ex vivo model of our study, the fibroblasts from CS-exposed and influenzainfected mice showed higher expression of $\alpha$-SMA with increased stress fibers, and more rapid cell proliferation with increased expression of growth factors. An increased number of fibroblasts was also noted in the CS-exposed and influenza-infected mice. It is known that in fibrotic responses, the fibroblasts play a major role in the production and deposition of interstitial collagen (27). As fibrosis progresses after inflammation, myofibroblasts are activated $(32,33)$ and $\alpha$-SMA expression, a marker of myofibroblasts, is enhanced in local fibroblasts $(34,35)$. Contraction of injured tissue is essential to reduce the size of the wound caused by the injury, and $\alpha$-SMA provides increased contractile activity of the fibroblasts (34). Furthermore, fibroblastic responses in the lung have been described in chronic lung disorders associated with CS exposure, such as COPD and pulmonary fibrosis (36). In this regard, our experimental model might be useful to elucidate the underlying mechanism by which CS exposure acts as an adverse risk factor in viral infection. We are actively working to identify the precise mechanisms by which CS exposure contributes to the rapid proliferation of fibroblasts after influenza viral infection.

In contrast to the surge of active TGF- $\beta 1$ in the later phase ( 24 days after infection) in CS-exposed, influenza virus-infected mice, CS exposure decreased the levels of TGF- $\beta 1$ in the early phase (6 days after infection). We speculate that the suppression of TGF- $\beta 1$ in the early phase might play a significant role in the enhanced inflammation observed in the CS-exposed, influenza virus-infected mice. Experimental evidence to support this notion comes from a previous study that demonstrated a dynamic and temporal role of TGF- $\beta$ at different time points in a murine model of myocardial infarction 
A

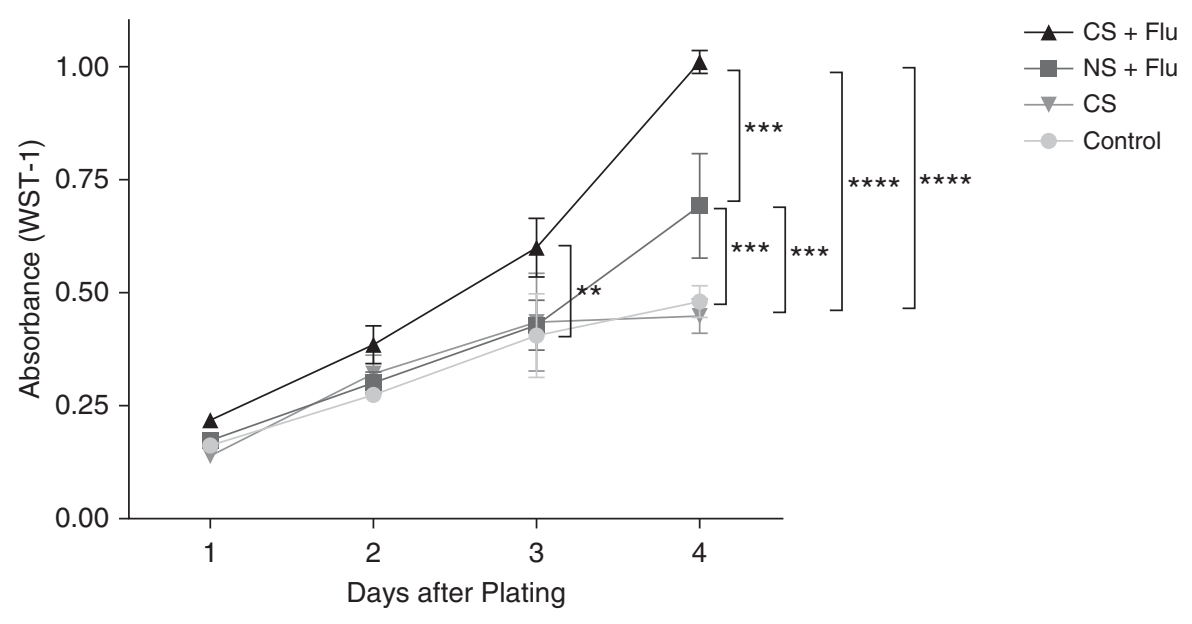

B
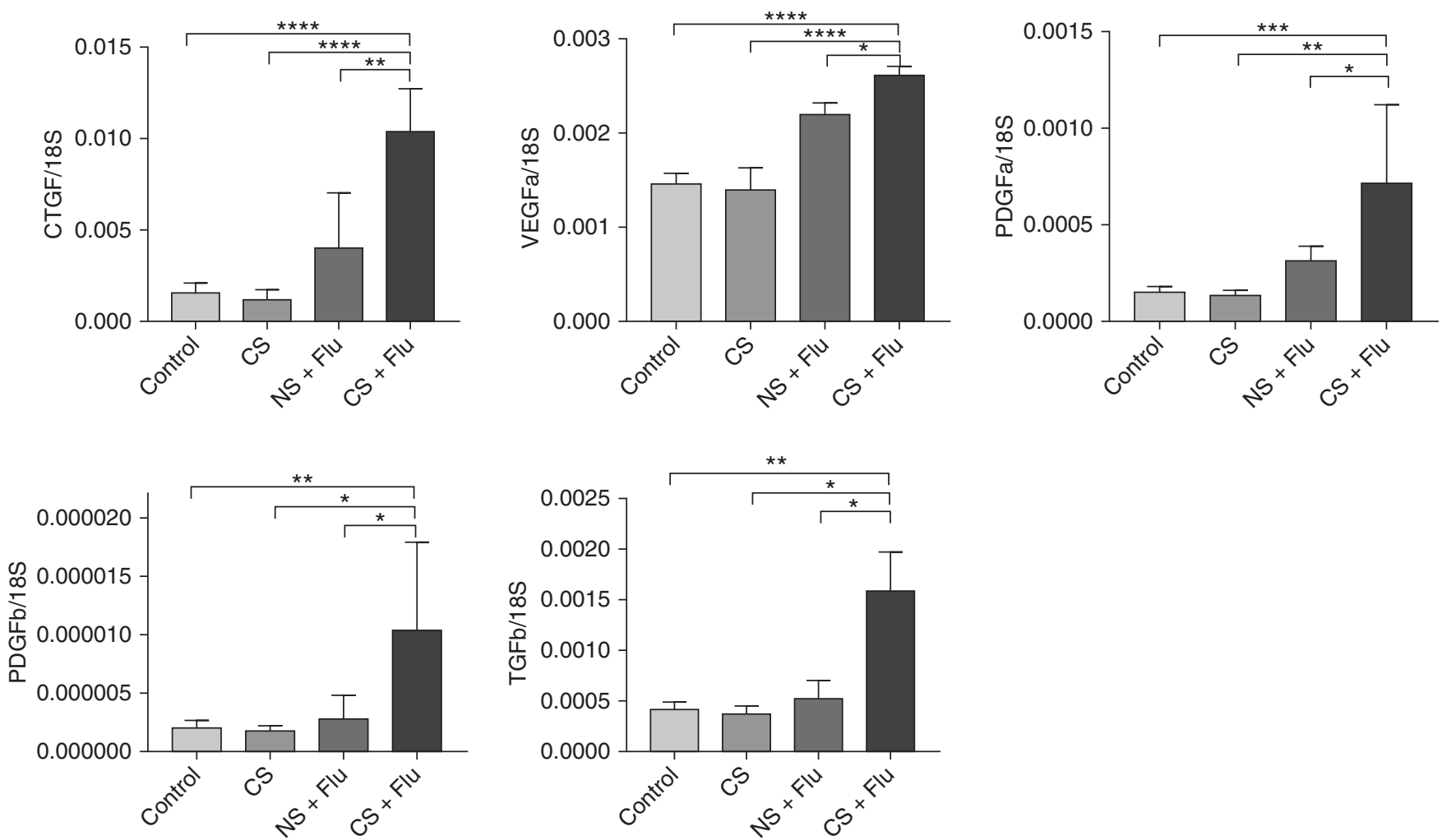

Figure 6. CS exposure increases proliferation in fibroblasts upon influenza infection by stimulating various growth factors. Fibroblasts were obtained from mice that were infected with influenza and either exposed to CS or kept in room air. As infection controls, fibroblasts from mice that remained in room air or were exposed to CS without infection were obtained. (A) A WST-1 assay was performed to measure the proliferation of fibroblasts. (B) The expression of various growth factors (e.g., CTGF, VEGF- $\alpha$, TGF- $\beta$, PDGF- $\alpha$, and PDGF- $\beta$ ) was measured in the fibroblasts and normalized to $18 S$. Representative data from three independent experiments performed in triplicates. ${ }^{\star} P<0.05 ;{ }^{\star \star} P<0.01 ;{ }^{\star \star \star} P<0.001$; ${ }^{\star \star \star \star} P<0.0001$. CTGF $=$ connective tissue growth factor; PDGF- $\alpha=$ platelet-derived growth factor $\alpha$; VEGF- $\alpha=$ vascular endothelial growth factor $\alpha$.

(37). Specifically, TGF- $\beta 1$ inhibition in the early postmyocardial infarction period exacerbated the degree of left-ventricular contractile dysfunction, and during the later phase, TGF- $\beta$ inhibition attenuated left-ventricular hypertrophy and interstitial fibrosis (37). Therefore, similar effects of TGF- $\beta 1$ may be taking place in the lungs in our model.

We show that anti-TGF- $\beta$ antibody treatment in CS-exposed mice was able to decrease the fibrotic response and improve recovery during influenza infection. Interestingly, many fibrotic changes were not completely blocked by the use of anti-TGF- $\beta$ antibodies, as we observed only a partial decrease in collagen deposition and accumulation of $\mathrm{FSP}^{+}$cells, 
A

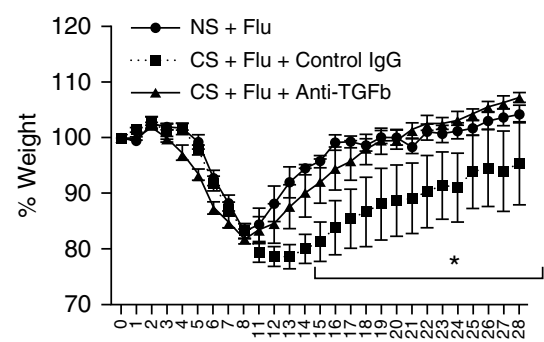

Days after Flu Infection

C
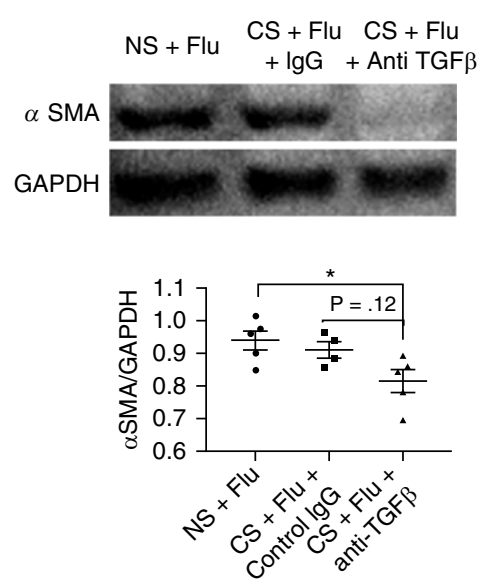

B

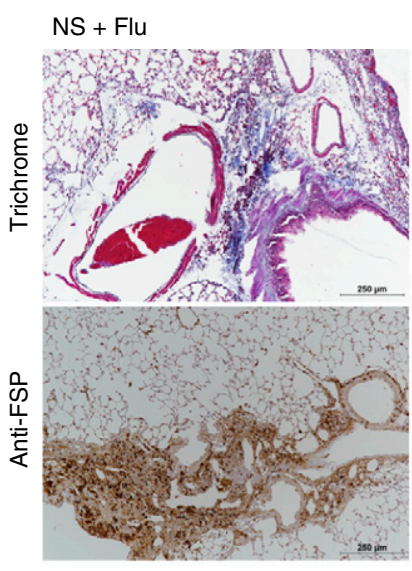

$\mathrm{CS}+\mathrm{Flu}+\lg \mathrm{G}$

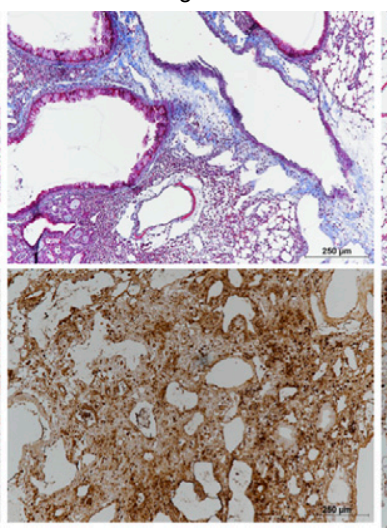

E

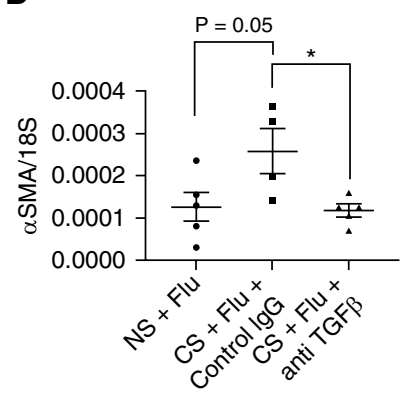

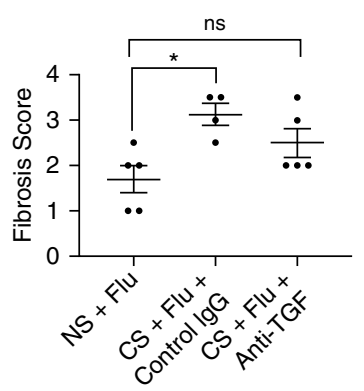

$\mathrm{CS}+\mathrm{Flu}+$ Anti TGF $\beta$

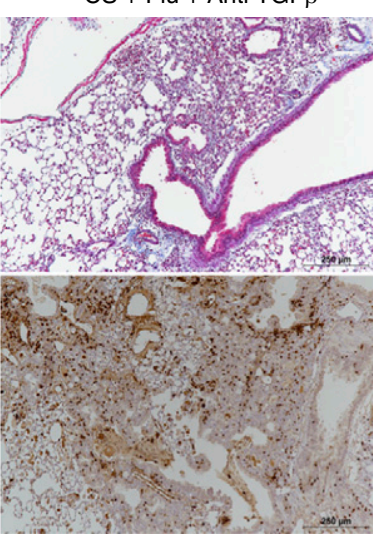

$\mathbf{F}$

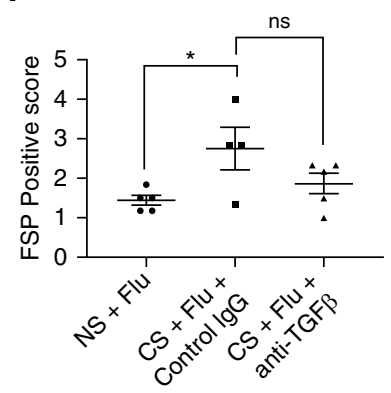

Figure 7. Anti-TGF- $\beta$ antibody treatment in CS-exposed mice ameliorates the fibrotic response and improves recovery during influenza virus infection. Mice were exposed to CS or NS for 2-3 weeks and then infected with influenza virus. The mice continued to receive the respective exposure even after infection. The CS-exposed mice were then divided into two groups to receive either anti-TGF- $\beta$ antibody ( 1 mg per mouse every other day starting from Day 12 after infection) or the same amount of control lgG. Mice were observed daily for weight changes and killed at Day 28 after infection to harvest the lungs. The overall morbidity measured as weight changes is shown in $A$. Lung sections were subjected to histological examination using Trichrome staining for collagen deposition (B, upper panel) and FSP (B, lower panel). (C) Protein and $(D)$ mRNA levels of $\alpha$-SMA were quantified in the lung tissues. Data are from one experiment performed with $n=4-5$ mice per each group. The extent of fibrosis on Trichrome-stained sections was quantified on a ( $E$ ) 4-point scale and FSP staining was quantified on a ( $F$ ) 5 -point scale. Scale bars: $250 \mu \mathrm{m}$. ${ }^{\star} P<0.05$, ns $=$ nonsignificant.

which were significantly increased by smoking. This incomplete blockage may be due to the late start of antibody treatment on Day 12. A significant increase in active TGF- $\beta$ in CS-exposed mice was already evident on Day 6 after infection. Day 12 was chosen as the starting point for anti-TGF- $\beta$ antibody treatment in CSexposed mice with influenza infection to avoid the immune effect of TGF- $\beta$ on viral clearance, which has been well established in our work and other studies of influenza infection (38). In our model, mice cleared the pathogens by Day 10, which we considered a decisive factor in initiating the use of anti-TGF- $\beta$ antibodies in our experiments. It is difficult to study antifibrotic responses independently of immunomodulatory effects in the presence of live infection. Although this issue was beyond the scope of this study, it would be interesting to explore as it relates to additional non-TGF- $\beta$ pathways that contribute to the fibrogenesis observed with CS exposure and influenza infection.

It is known that influenza infection is characterized by an early inflammatory phase followed by a later phase of tissue healing and fibroblastic processes. It is possible that the uncontrolled initial lung inflammation that occurred as a result of decreased TGF- $\beta 1$ led to the development of potentiated lung fibrosis in the CSexposed mice after influenza infection. Furthermore, it has been shown that monocyte-derived alveolar macrophages are able to drive lung fibrosis and persist in the lung over the life span (39). In this regard, it is interesting that we found that CS exposure resulted in a more persistent macrophage inflammatory response weeks after influenza virus infection. Further studies are warranted to define the role of pulmonary macrophages and their contribution to more severe fibrogenic responses in this context.

Studies by Gualano and colleagues in CS-exposed, influenza-infected mice showed transient increases in viral titers (40). However, other studies did not show significantly increased viral titers in CS-exposed, influenza-infected animals (16, 41,42 ). In our study, the viral titers were increased in CS-exposed mice compared with NS mice only at 3 days after infection, and no differences were noted at other time points, including Day 6 after infection, which was the time of peak viral titers. These studies suggest that CS may at most 
alter the initial susceptibility to influenza virus, and does not affect viral clearance mechanisms in the lungs, as evidenced by the similar viral loads in the later phase and similar clearance kinetics.

In conclusion, our study demonstrates that CS exposure in vivo exaggerates the fibroblastic response after influenza infection and induces the proliferation of lung fibroblasts with accumulation of collagen and myofibroblast properties. CS exposure in vivo also changes the kinetics of active TGF- $\beta$ production, suggesting that it plays dynamic roles in the initial inflammatory and later fibroblastic phases. This study may provide new insights into the role of CS exposure in the dysregulation of healing and fibroblastic processes after a respiratory viral infection. Our findings suggest that individuals infected with influenza virus may have an increased likelihood of developing a lung fibroblastic response in the setting of CS exposure and/or COPD. This work may improve our understanding of a subset of patients with COPD who have exacerbations with respiratory infections and subsequently develop fibrotic lung changes.

Author disclosures are available with the text of this article at www.atsjournals.org.

\section{References}

1. World Health Organization. Influenza (seasonal); 2016 [accessed 2017 Mar 17]. Available from: http://www.who.int/mediacentre/factsheets/fs211/en/.

2. Thompson WW, Shay DK, Weintraub E, Brammer L, Cox N, Anderson $\mathrm{LJ}$, et al. Mortality associated with influenza and respiratory syncytial virus in the United States. JAMA 2003;289:179-186.

3. Thompson WW, Shay DK, Weintraub E, Brammer L, Bridges CB, Cox $\mathrm{NJ}$, et al. Influenza-associated hospitalizations in the United States. JAMA 2004;292:1333-1340.

4. Nair H, Brooks WA, Katz M, Roca A, Berkley JA, Madhi SA, et al. Global burden of respiratory infections due to seasonal influenza in young children: a systematic review and meta-analysis. Lancet 2011;378: 1917-1930.

5. World Health Organization. Tobacco. 9 March 2018 [accessed 2018 Sep 2]. Available from: http://www.who.int/news-room/fact-sheets/detail/ tobacco.

6. Arcavi L, Benowitz NL. Cigarette smoking and infection. Arch Intern Med 2004;164:2206-2216.

7. Cohen S, Tyrrell DA, Russell MA, Jarvis MJ, Smith AP. Smoking, alcohol consumption, and susceptibility to the common cold. Am J Public Health 1993;83:1277-1283.

8. Kark JD, Lebiush M. Smoking and epidemic influenza-like illness in female military recruits: a brief survey. Am J Public Health 1981;71: 530-532.

9. Mandell LA, Wunderink RG, Anzueto A, Bartlett JG, Campbell GD, Dean $\mathrm{NC}$, et al. Infectious Diseases Society of America/American Thoracic Society consensus guidelines on the management of communityacquired pneumonia in adults. Clin Infect Dis 2007;44(Suppl 2): S27-S72.

10. Herridge MS, Tansey CM, Matté A, Tomlinson G, Diaz-Granados N, Cooper A, et al.; Canadian Critical Care Trials Group. Functional disability 5 years after acute respiratory distress syndrome. $N$ Engl $J$ Med 2011;364:1293-1304.

11. Nguyen-Van-Tam JS, Openshaw PJ, Hashim A, Gadd EM, Lim WS, Semple MG, et al.; Influenza Clinical Information Network (FLU-CIN). Risk factors for hospitalisation and poor outcome with pandemic A/H1N1 influenza: United Kingdom first wave (May-September 2009). Thorax 2010;65:645-651.

12. Kanegai CM, Xi Y, Donne ML, Gotts JE, Driver IH, Amidzic G, et al. Persistent pathology in influenza-infected mouse lungs. Am J Respir Cell Mol Biol 2016;55:613-615.

13. Hanshaoworakul W, Simmerman JM, Narueponjirakul U, Sanasuttipun W, Shinde V, Kaewchana S, et al. Severe human influenza infections in Thailand: oseltamivir treatment and risk factors for fatal outcome. PLoS One 2009;4:e6051.

14. Kark JD, Lebiush M, Rannon L. Cigarette smoking as a risk factor for epidemic $A(\mathrm{H} 1 \mathrm{~N} 1)$ influenza in young men. N Engl J Med 1982;307: 1042-1046.

15. Epstein MA, Reynaldo S, El-Amin AN. Is smoking a risk factor for influenza hospitalization and death? J Infect Dis 2010;201:794-795.

16. Kang MJ, Lee CG, Lee JY, Dela Cruz CS, Chen ZJ, Enelow R, et al. Cigarette smoke selectively enhances viral PAMP- and virus-induced pulmonary innate immune and remodeling responses in mice. J Clin Invest 2008;118:2771-2784.
17. Baumgartner KB, Samet JM, Stidley CA, Colby TV, Waldron JA. Cigarette smoking: a risk factor for idiopathic pulmonary fibrosis. $A m$ J Respir Crit Care Med 1997;155:242-248.

18. Antoniou KM, Hansell DM, Rubens MB, Marten K, Desai SR, Siafakas $\mathrm{NM}$, et al. Idiopathic pulmonary fibrosis: outcome in relation to smoking status. Am J Respir Crit Care Med 2008;177:190-194.

19. Wong LS, Martins-Green M. Firsthand cigarette smoke alters fibroblast migration and survival: implications for impaired healing. Wound Repair Regen 2004;12:471-484.

20. Hautamaki RD, Kobayashi DK, Senior RM, Shapiro SD. Requirement for macrophage elastase for cigarette smoke-induced emphysema in mice. Science 1997;277:2002-2004.

21. Liu J, Zhao MQ, Xu L, Ramana CV, Declercq W, Vandenabeele P, et al. Requirement for tumor necrosis factor-receptor 2 in alveolar chemokine expression depends upon the form of the ligand. $A m \mathrm{~J}$ Respir Cell Mol Biol 2005;33:463-469.

22. Kang MJ, Homer RJ, Gallo A, Lee CG, Crothers KA, Cho SJ, et al. IL-18 is induced and IL-18 receptor alpha plays a critical role in the pathogenesis of cigarette smoke-induced pulmonary emphysema and inflammation. J Immunol 2007;178:1948-1959.

23. Lawson WE, Polosukhin VV, Zoia O, Stathopoulos GT, Han W, Plieth D, et al. Characterization of fibroblast-specific protein 1 in pulmonary fibrosis. Am J Respir Crit Care Med 2005;171:899-907.

24. Lee CG, Hartl D, Lee GR, Koller B, Matsuura H, Da Silva CA, et al. Role of breast regression protein 39 (BRP-39)/chitinase 3-like-1 in Th2 and IL-13-induced tissue responses and apoptosis. J Exp Med 2009; 206:1149-1166.

25. Seluanov A, Vaidya A, Gorbunova V. Establishing primary adult fibroblast cultures from rodents. J Vis Exp 2010;(44):pii: 2033.

26. Tzouvelekis A, Yu G, Lino Cardenas CL, Herazo-Maya JD, Wang R, Woolard T, et al. SH2 domain-containing phosphatase-2 is a novel antifibrotic regulator in pulmonary fibrosis. Am J Respir Crit Care Med 2017;195:500-514.

27. Kendall RT, Feghali-Bostwick CA. Fibroblasts in fibrosis: novel roles and mediators. Front Pharmacol 2014;5:123.

28. Martin C, Papazian L, Payan MJ, Saux P, Gouin F. Pulmonary fibrosis correlates with outcome in adult respiratory distress syndrome. A study in mechanically ventilated patients. Chest 1995; 107:196-200.

29. Qiao J, Zhang M, Bi J, Wang X, Deng G, He G, et al. Pulmonary fibrosis induced by H5N1 viral infection in mice. Respir Res 2009; 10:107.

30. Pohlers D, Brenmoehl J, Loffler I, Muller CK, Leipner C, SchultzeMosgau S, et al. TGF- $\beta$ and fibrosis in different organs-molecular pathway imprints. Biochim Biophys Acta 2009;1792:746-756.

31. Kulkarni $A B$, Karlsson $S$. Transforming growth factor-beta 1 knockout mice. A mutation in one cytokine gene causes a dramatic inflammatory disease. Am J Pathol 1993;143:3-9.

32. Wynn TA. Integrating mechanisms of pulmonary fibrosis. J Exp Med 2011;208:1339-1350.

33. Gabbiani G. The myofibroblast in wound healing and fibrocontractive diseases. J Pathol 2003;200:500-503.

34. Hinz B, Celetta G, Tomasek JJ, Gabbiani G, Chaponnier C. Alphasmooth muscle actin expression upregulates fibroblast contractile activity. Mol Biol Cell 2001;12:2730-2741. 
35. Darby I, Skalli O, Gabbiani G. Alpha-smooth muscle actin is transiently expressed by myofibroblasts during experimental wound healing. Lab Invest 1990;63:21-29.

36. Karvonen HM, Lehtonen ST, Harju T, Sormunen RT, Lappi-Blanco E, Mäkinen JM, et al. Myofibroblast expression in airways and alveoli is affected by smoking and COPD. Respir Res 2013; 14:84.

37. Ikeuchi M, Tsutsui H, Shiomi T, Matsusaka H, Matsushima S, Wen J, et al. Inhibition of TGF-beta signaling exacerbates early cardiac dysfunction but prevents late remodeling after infarction. Cardiovasc Res 2004;64:526-535.

38. Denney L, Branchett W, Gregory LG, Oliver RA, Lloyd CM. Epithelialderived TGF- $\beta 1$ acts as a pro-viral factor in the lung during influenza A infection. Mucosal Immunol 2018;11:523-535.
39. Misharin AV, Morales-Nebreda L, Reyfman PA, Cuda CM, Walter JM, McQuattie-Pimentel AC, et al. Monocyte-derived alveolar macrophages drive lung fibrosis and persist in the lung over the life span. $J$ Exp Med 2017;214:2387-2404.

40. Gualano RC, Hansen MJ, Vlahos R, Jones JE, Park-Jones RA, Deliyannis $\mathrm{G}$, et al. Cigarette smoke worsens lung inflammation and impairs resolution of influenza infection in mice. Respir Res 2008;9:53.

41. Bauer CM, Zavitz CC, Botelho FM, Lambert KN, Brown EG, Mossman $\mathrm{KL}$, et al. Treating viral exacerbations of chronic obstructive pulmonary disease: insights from a mouse model of cigarette smoke and H1N1 influenza infection. PLoS One 2010;5:e13251.

42. Robbins CS, Bauer CM, Vujicic N, Gaschler GJ, Lichty BD, Brown EG, et al. Cigarette smoke impacts immune inflammatory responses to influenza in mice. Am J Respir Crit Care Med 2006;174:1342-1351. 